\title{
Evaluation of Drought Events in Various Climatic Conditions using Data-Driven Models and A Reliability-Based Probabilistic Model
}

\section{Ali Barzkar}

Graduate University of Advanced Technology

Mohammad Najafzadeh ( $\square$ moha.najafzadeh@gmail.com )

Graduate University of Advanced Technology-Kerman https://orcid.org/0000-0002-4100-9699

Farshad Homaei

Graduate University of Advanced Technology

\section{Research Article}

Keywords: Drought index, Precipitation, Evaporation, Climate change, Artificial Intelligence models, Reliability analysis

Posted Date: May 11th, 2021

DOI: https://doi.org/10.21203/rs.3.rs-475186/v1

License: (9) This work is licensed under a Creative Commons Attribution 4.0 International License. Read Full License

Version of Record: A version of this preprint was published at Natural Hazards on September 13th, 2021. See the published version at https://doi.org/10.1007/s11069-021-05019-7. 
${ }^{1}$ Graduate Student, Department of Water Engineering, Faculty of Civil and Surveying Engineering, Graduate University of Advanced Technology, Kerman, Iran, alibarzkar3307@gmail.com

${ }^{1 *}$ Assitant Professor, Department of Water Engineering, Faculty of Civil and Surveying Engineering, Graduate University of Advanced Technology, Kerman, Iran, moha.najafzadeh@gmail.com; m.najafzadeh@kgut.ac.ir (Corresponding Author)

${ }^{2}$ Assistant Professor, Department of Earthquake and Geotechnical Engineering, Faculty of Civil and Surveying Engineering, Graduate University of Advanced Technology, Kerman, Iran, f.homaei@kgut.ac.ir

Due to a wide range of socio-economic losses caused by drought over the past decades, having

a reliable insight of drought properties plays a key role in monitoring and forecasting the increasing or decreasing the temperature and consequently evapotranspiration can intensify or moderate the severity of drought events. Standardized Precipitation Evaporation Index (SPEI), as one of the most well-known indices in definition of drought situation, is applied based on 
Keywords: Drought index; Precipitation; Evaporation; Climate change; Artificial Intelligence

Drought events, known as one of the most severe climatic phenomena, can significantly affect

agricultural production and water resources management (Saadat et al. 2011). Due to the situations have been proposed by meteorologists with various perspectives based on different variables. One of the most comprehensive definitions provided by Palmer (1965). In accordance with this, drought is a period in which the amount of moisture or any other indicator has a negative anomaly compared to the average conditions of the region (Palmer 1965). Due to various influential factors of drought occurrence, drought types are generally divided into various groups: meteorological drought, agricultural drought, hydrological drought, and socioeconomic drought (Heim Jr 2002). Numerous indicators have been presented to assess the types 
Index (PDSI) (Palmer 1965), Surface Water Storage Index (SWSI) (Shafer and Dezman 1982),

Standardized Precipitation Index (SPI) (McKee, Doesken, and Kleist 1993) and Standardized 56

Precipitation Evaporation Index (SPEI) (Vicente-Serrano, Beguería, and López-Moreno 2010;

Bayissa et al., 2018). Among these indices, SPI and SPEI index are known as the most widely

used indices. The SPI has been widely applied in previous investigations due to its

In this regard, Potop and Mozny (2011) evaluated the new SPEI in the Czech Republic and proved the high potential of the SPEI to find various situations of drought event. Tornros and indicated the highest dependency with estimated soil moisture. In addition, Normalized of drought using the two indicators SPI and SPEI in the situation of climate changes in China. From their study, it was found that SPEI has a higher potential of visualizing drought in climate change conditions than SPI (Tan et al., 2015). Le et al. (2016) did research on the climatic 76 signals to predict SPEI in Vietnam's Hangu Province using an Artificial Neural Network (ANN). They found that the developed model could benefit from the development of long-term policies for reservoirs and irrigation operations and alternative plant plans in the field of 
drought risk. Mumtaz et al. (2018) conducted a study with the aim of developing a robust 80 drought modeling strategy to predict SPI at different time scales in Pakistan. In their research, 81 Adaptive Neuro Fuzzy Inference System (ANFIS) model was used to estimate the SPI. 82 Ultimately, the ANFIS model developed for six and 12 month time scales had more accuracy 83 than three-month SPI. Given the superiority of the ANFIS model and its potential of providing 84 reliable information about uncertainty, the proposed model can be used to predict drought risk 85 for strategic water and agricultural resource management decision making (Ali et al. 2018). 86 Additionally, Khan et al. (2020) explored for the first time the potential of developing drought 87 forecasting models in Pakistan using three advanced Machine Learning (ML) methods: 88 Random Forest (RF) and Support Vector Machine (SVM). From their investigations, it was 89 found that SPEI is directly related to the relative humidity of the Mediterranean Sea and the 90 northern district of the Caspian Sea. While in the temperate season, SPEI has a direct 91 relationship with the humid district southeast of the Bay of Bengal and the northern regions of 92 the Mediterranean Sea and the Caspian Sea. Liu et al. (2020) introduced a new drought index, 93 known as the integrated agricultural drought index (IDI), based on an ANN and Remote 94 Sensing (RS) data in northern China. They found that IDI based on a ML method could reduce 95 the hypothesis used in many existing indicators that input and output data (or meteorological 96 information) are linearly correlated. Additionally, Dikshit et al. (2021) applied Deep Learning 97 (DL) methodology to predict SPEI for New South Wales and Australia using data from the 98 period of 1901-2018. From their study, they found that the DL technique is capable of 99 forecasting accurately at short-term and long-term lead times.

One of the methods used to predict the drought event situations is the Artificial Intelligence 101 (AI) techniques which could detect efficiently general patterns/variations between drought 102 indices and meteorological data (e.g., Ozger et al., 2011; Belayneh et al. 2014; Abbot and 103 Marohasy 2014; Salcedo-Sanz et al. 2016). For instance, ANN (Djerbouai and Souag-Gamane 
From the literature review, it was found that some robust AI techniques such as Genehave two major advantages. Firstly, these AI models are capable of presenting reliable

On the contrary, the most frequently used-AI techniques (e.g., SVM, ANN, and ANFIS) to predict drought index which acted as a black box, were not capable of obtaining mathematical expressions based on meteorological data. Additionally, ignorance of this issue might be likely to reduce applicability of black box-based-AI models in comparison with formulation-basedAI models.

The current research work includes two major contributions. First, in order to create a mathematical model that incorporates the meteorological parameters affecting the SPEI, it is necessary to have empirical relationships based on AI models which can provide an accurate estimation of SPEI. In the case of second contribution, according to the random nature of the 
attention to the reliability analysis of SPEI during the last decade. In this way, it can be said that there is a ferocious demand for obtaining AI models-based-equations to accurately estimate SPEI and further reliability analysis.

In the current research, the performance of artificial intelligence models of Multivariate Adaptive Regression Splines (MARS), Gene Expression Programming (GEP) and Model Tree (MT) is examined for four various climatic conditions of Iran. After that, AI models are developed and additionally, the efficiency levels in the prediction of SPEI for all the climatic

\section{Overview of Case study}

Iran is a high plateau located in the northern hemisphere in the warm region and is one of the

arid and semi-arid regions of the world. As in many parts of the world in Iran, especially in

billion cubic meters are returned to the atmosphere through evapotranspiration. As a result, the total amount of renewable water per year is less than 2000 cubic meters for arid and very dry

(Kiafar et al. 2017). According to the various climatic conditions of Iran in this study, we 
The present study was conducted in four meteorological stations in the different climates of

Iran. In this regard, maximum temperature $\left(T_{\max }\right)$, minimum temperature $\left(T_{\min }\right)$, average

\section{Standardized Precipitation Evaporation Index}

At the end of the previous decade, Vicente et al. (2009) used the SPEI to calculate the annual is a subtle difference between two methods. The difference is that SPEI methodology uses the 


$$
\begin{aligned}
& P E T=16 K\left(\frac{10 T}{I}\right)^{m} \\
& m=6.75 \times 10^{-3} I^{3}-7.71 \times 10^{-5} I^{2}+1.79 \times \\
& 10^{-2} \\
& i=\left(\frac{T}{5}\right)^{1.514} \\
& K=\left(\frac{N}{12}\right)\left(\frac{N D M}{30}\right)
\end{aligned}
$$

In which, $T$ is the average monthly temperature $\left({ }^{\circ} \mathrm{C}\right), m$ is the coefficient of dependence on $\mathrm{I}, I$ 180 is the heat index or the sum of 12 months $i, K$ is the correction factor in terms of month and latitude, $N D M$ is the number of days in a month and $N$ denotes the maximum number of hours of radiation.

After calculating the evapotranspiration potential (PET), the difference between precipitation $(P)$ and PET for $i$ month obtained.

$$
D_{i}=P_{i}-P E T_{i}
$$

The values of $D$ at different time scales are obtained from the following equation.

$$
D_{n}^{k}=\sum_{n=0}^{k-1} P_{n-1}-P E T_{n-i}
$$

Where $k$ is the desired number of months and $n$ is the desired month in the calculation.

To calculate the drought index, three-parameter distribution is needed to cover the negative values in the $D$ data. The results of selecting the most appropriate distribution function show that the logarithmic logistic function fits well with the time series of data at various time scales. 190 Thus, the cumulative probability function of the $D$ data series based on the logarithmic logistic function is calculated as follows:

$$
F(x)=\left[1+\left(\frac{\alpha}{x+\gamma}\right)^{\beta}\right]^{-1}
$$


Where $\alpha$ is the scale parameter, $\beta$ is the shape parameter and $\gamma$ is the main parameter for $D$

values in the range $\gamma>D<\infty$.

Finally, the SPEI is calculated as standardized values of $F(x)$ :

$$
S P E I=W-\frac{L_{0}+L_{1} W+L_{2} W^{2}}{1+d_{1} W+d_{2} w^{2}+d_{3} w^{3}}
$$

in which, $W=\sqrt{-2 \ln (P)}$ which is valid for $P \leq 0.5$ and $P$ variable denotes the probability

of increasing the set values $d$. The values of $L_{0}, L_{1}$ and $L_{2}$ as well as $d_{1}, d_{2}$ and $\mathrm{d}_{3}$ are constant.

The classification of this index indicates that the SPEI situation changes from very extreme humidity (SPEI<-2) to very severe drought (SPEI>2), as seen in Table S1 (See Supplementary Materials).

\section{Gene-Expression Programming}

Gene expression programming (GEP) is a generalization of the two algorithms: Genetic 204 Algorithm (GA) and Genetic Programming (GP) (Koza and Koza 1992). GEP is a search model 205 which develops computer programs with various configurations such as mathematical 206 expressions, polynomial expressions, and logical expressions. Different shapes, similar to 207 decomposition trees, are combined in GP. The performance of the GA algorithm is based on 208 nature and based on the survival of the fittest. In this way, it first forms a population of 209 organisms and by applying a series of operators on this population, creates an optimal set that 210 has specific characteristics of the population (Ferreira 2006; Gholampour et al., 2017). GEP was firstly used by Ferreira (1999). In GEP, a relationship is established by chromosomes which have uncomplicated, certain length, and linear configurations. The GEP approach has five steps of development. The first step is to fix the fitness function of an individual program. 214 Mean Squared Error (MSE) is applied for evaluation of fitness function. The second stage is 
determining the terminals and the mathematical function to generate the chromosomes. The

third stage of development is identifying the structure of chromosomes. And more, the well-

matching algebraic operators are essentially fixed to establish a general equation among genes.

Finally, a board range of genetic operators are fixed (Ebtehaj et al. 2015).

In this study, in order to estimate the drought index using GEP model, GenXproTools5

software was used. In GEP modeling, maximum and minimum temperature, average

as an output parameter of the model. The settings used in GEP modeling to estimate SPEI are

given in Table S2. The best relationships extracted from 10,000 generations and 3 genes for

$$
\begin{aligned}
S P E I_{\text {Ramsar }}= & T_{\text {max }} \\
& \times \tanh \left(\left(\left(P_{24}+T_{\text {max }}\right)-\left(\left(P_{24}\right)^{\frac{1}{3}}\right)\right)-P_{24}\right) \\
& \left.+\left(\left(\operatorname{Min}\left(\left(\left(T_{\text {max }}\right)^{\frac{1}{3}}\right)^{\frac{1}{3}}, T_{\text {max }}\right)\right) \times T_{\text {max }}\right)-T_{\text {max }}\right) \\
& +\left(\left(\frac{\tanh \left(U_{2}\right)+\left(T_{\text {max }}-T_{\text {mean }}\right)}{2}\right)^{\frac{1}{3}}+\left(\left(P_{24}\right)^{\frac{1}{3}}-\left(T_{\text {max }}\right.\right.\right. \\
& \left.\left.\left.+T_{\text {max }}\right)\right)\right)
\end{aligned}
$$




$$
\begin{aligned}
& S P E I_{\text {Ahvaz }}=\left(\left(\tanh \left(\tanh \left(T_{\text {min }}\right)^{\frac{1}{3}}\right)\right)\right. \\
& \left.\times\left(\tanh \left(\frac{\left(U_{2}-T_{\max }\right)+\left(\operatorname{Max}\left(T_{\text {mean }}, U_{2}\right)\right.}{2}\right)\right)\right) \\
& \left.+\tan ^{-1}\left(\frac{\frac{\left(U_{2} \times T_{\max }\right)+\left(U_{2} \times P_{24}\right)}{2}}{\frac{\left(T_{\text {mean }}{ }^{2}\right)+\left(1-P_{24}\right)}{2}}\right)\right)+\left(\operatorname { t a n h } \left(\left(\left(P_{24}+R_{H}\right)\right.\right.\right. \\
& \left.\left.\left.+\left(T_{\max }+R_{H}\right)\right)-\left(\frac{\left(T_{\text {mean }}\right)^{2}+\left(1-R_{H}\right)}{2}\right)\right)\right) \\
& S P E I_{\text {Tabriz }}=\left(\frac{\tan ^{-1}\left(\frac{T_{\max }}{P_{24}}\right)+\left(e^{U_{2}}, R_{H}\right)^{\frac{1}{3}}}{2}\right) \\
& +\left(\left(\left(\frac{P_{24}}{T_{\max }}\right)-T_{\max }\right)-\left(T_{\max }-T_{\max }\right)\right) \\
& \left.\times\left(\frac{\left(T_{\text {mean }}+T_{\min }\right)}{T_{\max }^{2}}\right)\right) \\
& +\left(\left(\left(-\left(\tanh \left(U_{2}\right)\right)-\left(\frac{\left(T_{\text {mean }}\right)^{2}}{P_{24}}\right)\right) \times\left(T_{\text {max }}+T_{\text {min }}\right)^{\frac{1}{3}}\right)\right.
\end{aligned}
$$




$$
\begin{aligned}
S P E I_{\text {Kerman }}= & \left(\left(T_{\text {max }}-T_{\text {min }}\right)^{\frac{1}{3}}-T_{\text {mean }}\right)+\left(\frac{\left(P_{24}-T_{\text {min }}\right)}{2}\right)^{\frac{1}{3}} \\
& +\left(\operatorname{Max}\left(T_{\text {max }}, R_{H}\right)\right. \\
& \left.\times \tan ^{-1}\left(R_{H}\right)\right)-\operatorname{Min}\left(\left(U_{2}\right)^{2},\left(R_{H}-T_{\text {mean }}\right)\right)^{\frac{1}{3}} \\
& +\left(\left(\frac{-T_{\text {min }} \times\left(\left(T_{\text {min }}-U_{2}\right)+P_{24}\right)}{2}\right)^{\frac{1}{3}}\right)^{\frac{1}{3}}
\end{aligned}
$$

\section{Multivariate Adaptive Regression Spline (MARS)}

The MARS model, as a non-parametric regression method, was firstly proposed by Friedman

(1991). The MARS model is capable of providing flexible, precise, and fast regression models

for predicting continuous and numerical output variables (Yilmaz et al. 2018). Additionally,

MARS has the capability to process the large volume of high-dimensional data. The main merit

of MARS is the capability to express the complex and nonlinear relationship between the

predictor and response variables. The MARS model can model the equations between the

predicted and observed independent variables. In the modeling process, the input variables (or

vectors) are grouped into intervals (subsets) and the base functions which are proportional to

each interval. The base function denotes information about input variables. A minus function

is determined in a limited range, and its start and end points are named nodes. The node

represents the point at which performance behavior changes (Mehdizadeh et al. 2017; Kisi and

Parmar 2016; Fernández et al. 2013; Balshi et al. 2009 ). The basic functions of the relationship

$$
\begin{aligned}
& y=\max (0, x-k) \\
& y=\max (0, k-x)
\end{aligned}
$$


Where $K$ is a node constant called (threshold limit), $x$ is the input variable and $y$ is the target

variable. Also, the general relationship is described by the following formula:

$$
\Gamma(t)=C_{0}{ }^{\prime}+\sum_{i=1}^{e} C_{i} \cdot \lambda_{i}(t)
$$

where $\lambda_{i}, C_{i}, C_{o}{ }^{\prime}$ and $e$ are the base functions, fixed functions, initial constants and number of functions respectively.

The MARS model consists of two development stages. In the first stage (step forward), MARS

predicts the dependent variable (or target values) with a constant value. This is the average

value of the data of the target variable. This step will continue until all possible basic functions

are added to the model. In step one, a complex and overly complex model is generated with a

fair number of nodes. In the next step (step back), less significant basic functions are detected

by using MARS model; therefore, these basic functions are eliminated by the pruning process.

This process continues to check all the basic functions. Ultimately, an optimal model is obtained (Mehdizadeh et al., 2017).

In this research, the MARS model has been implemented using the programmed codes of

MATLABR2013a software, so that the number of basic functions (NBF) for the Ramsar,

Ahvaz, Tabriz and Kerman stations are equal to 19,37,32 and 33 respectively; additionally,

the initial constant values in the models are fixed $-1.387,0.16632,0.81793$ and -1.4038 , 
Machine Learning (ML) techniques, especially decision tree modeling, have shown successful applications in water resources and flood management (Bhattacharya and Solomatine 2003; in the family of decision tree, was proposed by Quinlan (1992) for predicting continuous data. M5MT is one of the data mining methods that is inspired by the nature of trees, i,e., it has a structure similar to a tree (leaf branch root) and similar processes (growth and pruning)

$$
S D R=s d(T)-\sum_{1}^{m}\left(\frac{\left|M_{i}\right|}{|S|} s d\left(M_{i}\right)\right)
$$

Where $S D R$ is the standard deviation reduction, $S D$ is the standard deviation, $S$ is the input of each node and $M_{i}$ is the input of the $i$ th node.

Weka3.9 software was used to implement the M5MT model. The tree structure of the M5 
Warm climate, MT created 13 rules with two splitting variables: $P_{24}$ and $T_{\text {mean }}$. In Tabriz station

with Wet-Cold condition, linear equations given by MT have six rules with two splitting

variables $P_{24}$ and $T_{\text {mean }}$. In the Arid-Warm climate, SPEI values were predicted by 15 rules and

four splitting variables (i.e., $P_{24}$ and $T_{\text {mean }}, T_{\max }$, and $R_{\mathrm{H}}$ ). Also, the relationships extracted from

\section{Results and Discussions}

Results of this study are presented in two sections: $(i)$ statistical measures of AI models to

\section{Definition of statistical measures}

To evaluate the performance of under proposed approaches and identify the best ones for drought index estimation in each climate, several statistical measures were employed. In this

$$
\begin{aligned}
& I A=1-\frac{\sum_{i=1}^{N}\left(S P E I_{P r e}^{i}-S P E I_{O b s}^{i}\right)^{2}}{\sum_{i=1}^{N}\left(\left|S P E I_{P r e}^{i}-\overline{S P E I}_{P r e}\right|+\left|S P E I_{O b s}^{i}-\overline{S P E I}_{O b s}\right|\right)^{2}} \\
& R M S E=\sqrt{\frac{\sum_{i=1}^{N}\left(S P E I_{P r e}^{i}-S P E I_{O b s}^{i}\right)^{2}}{N}} \\
& M A P E=\frac{\sum_{i=1}^{N}\left|\frac{S P E I_{O b s}^{i}-S P E I_{P r e}^{i} \mid}{S P E I_{O b s}^{i}}\right|}{N} \times 100 \\
& B I A S=\frac{\sum_{i=1}^{N}\left(S P E I_{P r e}^{i}-S P E I_{O b s}^{i}\right)}{N} \\
& S I=\sqrt{\frac{1}{N} \sum_{i=1}^{N}\left[\left(S P E I_{P r e}^{i}-\overline{S P E I}_{P r e}\right)-\left(S P E I_{O b s}^{i}-\overline{S P E I}_{O b s}\right)\right]^{2}}
\end{aligned}
$$


Where $N$ is the number of samples, SPEI ${ }_{\text {Obs }}^{i}$ is the measured SPEI, SPEI $I_{\text {Pre }}^{i}$ is the predicted SPEI, $\overline{S P E I}_{O b s}$ is the mean of measured SPEI, and $\overline{S P E I}_{P r e}$ is the mean of estimated SPEI.

IA is a dimensionless parameter that is used as a standard criterion for evaluating the error of

models and has a value in the range of $[0,1]$. This index is indicative of the ratio of the mean

negative value and includes a value in the range of $[0,6+\infty)$. MAPE calculates the average

absolute percentage of error in a set of predicted values. The values of this index are expressed

as a percentage and, like RMSE, which low values of MAPE indicate good performance of the

model. The BIAS represents the difference between the means of the observed and predicted

data. The closer the values are to 0 , the better the model performance. If the BIAS $>0$ over

prediction for numerical model (the mean of SPEIPre values are greater than the mean of

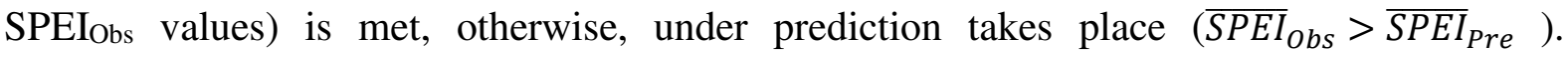

Ultimately, SI value indicates the percentage of RMS difference with respect to the mean of

This section evaluates the performances of the GEP, MARS and M5MT for the SPEI estimation. Additionally, strengths and weaknesses associated with models performance in the prediction of SPEI in each climate are discussed.

\section{Performance of Data-driven Models}

Table 3 indicates the quantitative results of AI techniques in the SPEI prediction for the training 
MAPE (0.083) than GEP (IA=0.988, RMSE=0.211, and MAPE=-3.232) and M5MT

$(\mathrm{IA}=0.988, \mathrm{RMSE}=0.211$, and MAPE=-3.232). In the Ramsar station, values of SI indicated

that MARS had the highest level of accuracy $(\mathrm{SI}=0.542)$ in comparison with GEP $(-20.569)$ with IA of 0.997, RMSE of 0.121, and MAPE of 0.157 provides more accurate SPEI estimation in comparison with GEP and M5MT techniques. Furthermore, the results of Table 3 showed superiority of M5MT (IA=0.993 and RMSE=0.179) over GEP model (IA=0.993 and RMSE $=0.179$ ). In the Arid-Cold conditions, the performance of MARS model for the Tabriz station had the highest level of precision in the SPEI prediction (IA=0.995, RMSE $=0.130$, and MAPE $=0.061)$ when compared to the GEP $(\mathrm{IA}=0.981, \mathrm{RMSE}=0.281$, and MAPE $=1.325)$ and M5MT (IA=0.990, RMSE=0.207, and MAPE=0.924). Similarly, for the Kerman station, the 338 statistical measures associated with the MARS model indicated comparatively better 339 performance than other AI models.

Fig.1 illustrates performance of AI models for various climates in the training stage. As seen 341 in Fig.1a, it was found that all the values of SPEI predicted by the MARS model had the best performance whereas, in Fig.1b, GEP model had the highest level of scattering data (SI=343 20.569) in the Temperate-Wet climate. In the Wet-Warm climate, Fig.1e illustrated the 344 graphical performance of GEP model had significant over/under prediction. In Fig.1h, GEP 345 model under predicted SPEI between -3 and -2 for the Tabriz station, whereas over prediction 346 was seen for SPEI=2-3. In the Kerman station with Arid-Warm climate, Fig.1k indicated that 347 GEP model under/over predicted partially for the SPEI=-3-0 and additionally, for SPEI=2-3, 348 under prediction was observed. Scatter plot observed in Fig.1j illustrated satisfying 349 performance of MARS model and Fig.1 indicated relative good performance of M5MT.

As indicated in Table 4, the results of AI techniques in the SPEI estimation were provided in 351 the testing stages. Statistical measures given in Table 4 proved that M5MT technique had the 
highest potential of SPEI prediction in all the climatic situations in comparison with MARS

and GEP models. In the case of Temperate-Warm climate, M5MT approach had the best

performance $(\mathrm{IA}=0.997, \mathrm{RMSE}=0.107$, and $\mathrm{MAPE}=0.744)$ when compared to the GEP

$(\mathrm{IA}=0.981, \mathrm{RMSE}=0.250$, and MAPE $=-2.254)$ and MARS $(\mathrm{IA}=0.996, \mathrm{RMSE}=0.148$, and

MAPE=-0.207). And more, values of BIAS and SI parameters indicated superiority of M5MT

over other AI models in the Ramsar station. In the Wet-Warm climate, MARS model had the

lowest level of accuracy in the SPEI prediction than GEP $(\mathrm{IA}=0.923, \mathrm{RMSE}=0.605, \mathrm{MAPE}=-$

2.193) and M5MT (IA=997, RMSE=0.107, and MAPE=0.744) techniques. In addition, BIAS

and SI values indicated superiority of M5MT (BIAS=0.004 and SI=2.093) over GEP model

(BIAS=0.077 and SI=-4.532) and MARS (BIAS=0.583 and SI=-0.487) in the Ahvaz station.

In the case of Arid-Cold climate, the M5MT technique stand at the highest level of efficiency

in the SPEI prediction $(\mathrm{IA}=0.989, \mathrm{RMSE}=0.218$, and MAPE $=-0.887)$ in comparison to the

GEP $(\mathrm{IA}=0.989, \mathrm{RMSE}=0.278$, and MAPE $=-1.222)$ and MARS $(\mathrm{IA}=0.932, \mathrm{RMSE}=0.334$, and

MAPE=-0.229). For the Arid-Warm climate in the Kerman station, the statistical results related

to the M5MT provided relatively better efficiency in the SPEI estimation than GEP and MARS

models.

Fig.2 presented the performance of AI models for different climatic situations in the testing over/under predictions (SI=4.851) for the SPEI values between 1 and 2. Additionally, Fig.2c depicted insignificant over/under predictions for the performance of M5MT for SPEI between 
relatively satisfying efficiency in the prediction of SPEI values. In the case of the Arid-Warm

climate, as illustrated in Fig.21, the graphical performance of the GEP model indicated

remarkable over prediction for the SPEI values between -3 and -1 , whereas, for the SPEI=1-3,

\section{Reliability-based probabilistic assessment of drought event}

For a reliability-based probabilistic assessment of drought events, it is essential to address the

problem with a limit-state function (LSF). In this procedure, the LSF is used to describe the

exceedance of Standardized Precipitation Evaporation Index (SPEI) from presumed values.

Moreover, the uncertainty from the random nature of the effective parameters (or

meteorological information) in the problem is addressed by introducing a series of random

based on the database. These parameters are used to assess the SPEI by considering the

randomness of each climatic variables. Hence, the next section deals with developing the

\section{Probabilistic distribution of random parameters}

The measured data for climate parameters have been seen to change randomly. For such statistical data, results were reported in the form of the mean, maximum, and minimum values. However, to describe the yearly variation of these parameters, it would be much appropriate to develop a probabilistic distribution for these parameters. In this form, the effect of variation in 
random parameters. In this procedure, the cumulative distribution of the presumed distribution

is compared with the numerical cumulative frequency of the random parameter. Then the

$$
D_{n}=\max _{x}\left|F_{X}(r)-G_{n}(r)\right| \leq D_{n}^{\kappa}
$$

Where, $G_{n}(r)$ and $F_{x}(r)$ presents the numerical and theoretical cumulative distribution of the satisfies the $D_{n}<D_{n}{ }^{\mathrm{K}}$ condition is selected as the well-suited theoretical distribution.

\section{Probabilistic model for SPEI}

As mentioned before, a limit-state function (LSF) is employed in reliability methods for defining the boundary between the failure and safety of the problem. When it comes to 
Evaporation Index (SPEI) from a specific value. The LSF can be expressed in the form of a mathematical relation which is a function of random variables:

$$
\text { Limit state function : } \operatorname{LSF}(\underset{o}{x})=S P E I_{A}-S P E I_{M}(\underset{o}{x})
$$

Where $S P E I_{A}$ indicates the "Acceptable" threshold for the Standardized Precipitation 426 Evaporation Index and $S P E I_{M}$ is the "Measured" value from the realization of random input parameters:

$$
S P E I_{M}=h\left(T_{\text {max }}, T_{\text {min }}, T_{\text {mean }}, P_{24}, R_{H}, U_{2}\right)+\varepsilon
$$

In this equation, $h$ is the function or algorithm and $\varepsilon$ is the model error in the form of a random variable. $\varepsilon$ is also known as the "uncertainty" parameter and shows the difference between the observed SPEI and the predicted ones from M5MT (Tables S7\&S8) for all the climatic situations. This parameter is usually considered as a random parameter with a normal distribution (Mahsuli and Haukaas 2013). As shown in Fig.S4, the residual quantile of the error against the normal quantiles was distributed along the $45^{\circ}$ line which indicates the normality of errors.

$$
\begin{cases}\operatorname{LSF}\left(x_{\%}\right)<0 & \text { Failure } \\
\operatorname{LSF}\left(\begin{array}{c}
x \\
\%
\end{array}\right)=0 & \text { Limit state surface (Neural) } \\
\operatorname{LSF}\left(\begin{array}{c}
x \\
\%
\end{array}\right)>0 & \text { Safe }\end{cases}
$$

Reliability assessment of drought events through SPEI

Since the effective parameters in drought events have a random nature, results are sensitive to 
random parameters have a large dispersion. In this case, probabilistic methods are more suitable approaches for assessing the event since they consider both randomness and uncertainty of decision making. By employing the reliability-based probabilistic analysis, the probability of exceedance $(P E)$ (or probability of failure $\left(p_{f}\right)$ ) for $S P E I$ is measured. To this end, the violation of the LSF is assessed for different realizations of input parameters.

As shown in Fig.3, the realization of seven input variables (including the error) is generated through their probabilistic distribution. These values are used to assess $\mathrm{SPEI}_{M}$. Then the violation of the LSF is evaluated for estimating the failure probability:

$$
\begin{aligned}
p_{f}=P\left(S_{P E I_{A}}-S P E I_{M} \leq 0\right) & =P[L S F \leq 0] \\
& =\iint_{L S F \leq 0} \ldots \int f\left(X_{1}, X_{2}, \ldots, X_{n}\right) d X_{1} d X_{2}, \ldots, d X_{n}
\end{aligned}
$$

Where $X_{1}, X_{2}, \ldots, X_{n}$ are the limit state function input variables.

In this study, the Monte-Carlo scenario sampling was used for estimating $p_{f}$ for each $\mathrm{SPEI}_{A}$. To this end, realization for LSF is obtained from the scenario sampling of input parameters. Then the probability of exceedance is assessed by computing the ratio of the number of samples with failure $L S F$ to the total number of sampling:

$$
p_{f}=\frac{1}{N} \sum_{i=1}^{N} I\left(X_{1}, X_{2}, \ldots, X_{n}\right) \quad, I\left(X_{1}, X_{2}, \ldots, X_{n}\right)=\left\{\begin{array}{lll}
1 & \text { if } & \operatorname{LSF}\left(X_{1}, X_{2}, \ldots, X_{n}\right) \leq 0 \\
0 & \text { if } & \operatorname{LSF}\left(X_{1}, X_{2}, \ldots, X_{n}\right)>0
\end{array}\right.
$$

Fig.S5 depicts the exceedance probabilities for different values of SPEI given by Eq.(24) where 455 the randomness and uncertainty in each climatic variable were considered. The exceedance 456 probability $(P E)$ measures the chance of experiencing an event and how probable is it for an event to pass a specific limit (i.e. $\mathrm{SPEI}_{A}$ ). Fig.S5 illustrated a larger value of PE for the smaller values of SPEI in all the synoptic stations. In Fig.S5, all the curves follow a descending trend which is indicative of less $P E$ for larger values of SPEI. To characterize the situation of drought 
for the case study areas, specific ranges of SPEI are introduced by quite a few descriptive terms,

as seen in Table 3. In the Ahvaz station with Arid-Warm climate, it was found that there are

$85 \%$ to $99 \%$ chances for a climatic situation to exceed the "Very Severe Drought", indicating

SPEI varies from -5 to -2 . As chance declined to $80 \%$, the situation of "Severe Drought" was

met when SPEI values changed from -1.5 to -1.99 . SPEI values in the "Moderate Drought"

\section{Conclusion}

The current investigation aimed to design a probabilistic framework for drought situations by using three AI models (i.e., MARS, GEP, and M5MT) by considering the SPEI evaluation in various climatic situations: Temperate-Warm, Wet-Warm, Arid-Cold, and Arid-Warm. To develop the AI models, the six meteorological variables were considered. MARS models of three genes with satisfying accuracy level. In addition, M5MT provided a set of 
the prediction of SPEI. Therefore, the results of M5MT, as the most efficient equations in all

the climates, were used to propose probabilistic models in order to evaluate the drought

situations of the climates in the four case study areas. Through results of reliability analysis in

the Ahvaz station, in the case of humidity situations, probability of exceedance (PE) values

obtained below $33 \%$ indicated humid climate with various severities from "Medium Humidity"

490

for $25 \%-33 \%$ to "Very Extreme Humidity" for $\mathrm{PE}<15 \%$. For other climatic situations, the

491

analysis of PE values had the same trend as it was found for the Wet-Warm climate in the

Ahvaz station.

493

494

\section{Ethical Approval}

495

All procedures performed in studies involving human participants were in accordance with the ethical standards of the institutional and/or national research committee and with the 1964

\section{Consent to Participate}

Informed consent was obtained from all individual participants included in the study.

\section{Consent to Publish}

All the authors give the Publisher the permission of the authors to publish the research work.

\section{Authors Contributions}

Ali Barzkar; Collecting meteorological data and computing the SPEI, Performing AI model,

\section{Funding}

No funds, grants, or other support was received.

There is no conflict of interest. 
The data are not publicly available due to restrictions such their containing information that

Ang, A. H.-S., \& Tang, W. H. (2007). Probability concepts in engineering planning and 524 design: Emphasis on application to civil and environmental engineering: Wiley. 525

Abbot, John, and Jennifer Marohasy. 2014. 'Input selection and optimisation for monthly rainfall forecasting in Queensland, Australia, using artificial neural networks', Atmospheric research, 138: 166-78.

Ali, Mumtaz, Ravinesh C Deo, Nathan J Downs, and Tek Maraseni. 2018. 'An ensembleANFIS based uncertainty assessment model for forecasting multi-scalar standardized precipitation index', Atmospheric research, 207: 155-80.

Bayissa Y, Maskey S, Tadesse T, Van Andel SJ, Moges S, Van Griensven A, Solomatine D. 533 2018. Comparison of the Performance of Six Drought Indices in Characterizing Historical 534

Drought for the Upper Blue Nile Basin, Ethiopia. Geosciences, 8(3), 81.

Balshi, Michael S, A David McGuire, Paul Duffy, Mike Flannigan, John Walsh, and Jerry Melillo. 2009. 'Assessing the response of area burned to changing climate in western boreal North America using a Multivariate Adaptive Regression Splines (MARS) approach', Global Change Biology, 15: 578-600.

Bartlett, Darius, and Ramesh Singh. 2018. Exploring Natural Hazards: A Case Study Approach (CRC Press).

Belayneh, A, J Adamowski, B Khalil, and B Ozga-Zielinski. 2014. 'Long-term SPI drought forecasting in the Awash River Basin in Ethiopia using wavelet neural network and wavelet support vector regression models', Journal of Hydrology, 508: 418-29.

Berson, Alex, Stephen Smith, and Kurt Thearling. 1999. Building data mining applications for CRM (McGraw-Hill Professional).

Bhattacharya, Biswanath, and Dimitri P Solomatine. 2003. "Neural Networks and M5 model trees in modeling water level-discharge relationship for an Indian river." In ESANN, 407-12.

Deo, R.C., Salcedo-Sanz, S., Carro-Calvo, L. and Saavedra-Moreno, B., 2018. Drought prediction with standardized precipitation and evapotranspiration index and support vector regression models. In Integrating disaster science and management (pp. 151174). Elsevier. 
Djerbouai, Salim, and Doudja Souag-Gamane. 2016. 'Drought forecasting using neural networks, wavelet neural networks, and stochastic models: case of the Algerois Basin in North Algeria', Water Resources Management, 30: 2445-64.

Ebtehaj, Isa, Hossein Bonakdari, Amir Hossein Zaji, Hamed Azimi, and Ali Sharifi. 2015. 'Gene expression programming to predict the discharge coefficient in rectangular side weirs', Applied Soft Computing, 35: 618-28.

Fernández, JR Alonso, C Díaz Muñiz, PJ Garcia Nieto, FJ de Cos Juez, F Sánchez Lasheras, and MN Roqueñí. 2013. 'Forecasting the cyanotoxins presence in fresh waters: A new model based on genetic algorithms combined with the MARS technique', Ecological engineering, 53: 68-78.

Ferreira, Candida. 2001. 'Gene expression programming: a new adaptive algorithm for solving problems', arXiv preprint cs/0102027.

Ferreira, Cândida. 2006. Gene expression programming: mathematical modeling by an artificial intelligence (Springer).

Gholampour, Aliakbar, Amir H Gandomi, and Togay Ozbakkaloglu. 2017. 'New formulations for mechanical properties of recycled aggregate concrete using gene expression programming', Construction and Building Materials, 130: 122-45.

Gibbs, WJ, and JV Maher. 1967. 'Rainfall deciles as drought indicators, bureau of meteorology bulletin no. 48', Commonwealth of Australia, Melbourne, 29.

Heim Jr, Richard R. 2002. 'A review of twentieth-century drought indices used in the United States', Bulletin of the American Meteorological Society, 83: 1149-66.

Iqbal, Muhammad Farjad, Qing-feng Liu, Iftikhar Azim, Xingyi Zhu, Jian Yang, Muhammad Faisal Javed, and Momina Rauf. 2020. 'Prediction of mechanical properties of green concrete incorporating waste foundry sand based on gene expression programming', Journal of hazardous materials, 384: 121322.

Khan, Najeebullah, DA Sachindra, Shamsuddin Shahid, Kamal Ahmed, Mohammed Sanusi Shiru, and Nadeem Nawaz. 2020. 'Prediction of droughts over Pakistan using machine learning algorithms', Advances in Water Resources, 139: 103562.

Kiafar, Hamed, Hosssien Babazadeh, Pau Marti, Ozgur Kisi, Gorka Landeras, Sepideh Karimi, and Jalal Shiri. 2017. 'Evaluating the generalizability of GEP models for estimating reference evapotranspiration in distant humid and arid locations', Theoretical and applied climatology, 130: 377-89.

Kisi, Ozgur, and Kulwinder Singh Parmar. 2016. 'Application of least square support vector machine and multivariate adaptive regression spline models in long term prediction of river water pollution', Journal of Hydrology, 534: 104-12.

Koza, John R, and John R Koza. 1992. Genetic programming: on the programming of 597 computers by means of natural selection (MIT press).

Le, Manh Hung, Gerald Corzo Perez, Dimitri Solomatine, and Luong Bang Nguyen. 2016. 'Meteorological drought forecasting based on climate signals using artificial neural network-a case study in Khanhhoa Province Vietnam', Procedia Engineering, 154: 1169-75. 'Elucidating diverse drought characteristics from two meteorological drought indices (SPI and SPEI) in China', Journal of Hydrometeorology, 21: 1513-30. 
Mavromatis, T. 2007. 'Drought index evaluation for assessing future wheat production in Greece', International Journal of Climatology: A Journal of the Royal Meteorological Society, 27: 911-24.

McKee, Thomas B, Nolan J Doesken, and John Kleist. 1993. "The relationship of drought frequency and duration to time scales." In Proceedings of the 8th Conference on Applied Climatology, 179-83. Boston.

Mehdizadeh, Saeid, Javad Behmanesh, and Keivan Khalili. 2017. 'Using MARS, SVM, GEP and empirical equations for estimation of monthly mean reference evapotranspiration', Computers and Electronics in Agriculture, 139: 103-14.

Mouatadid, Soukayna, Nawin Raj, Ravinesh C Deo, and Jan F Adamowski. 2018. 'Input selection and data-driven model performance optimization to predict the Standardized Precipitation and Evaporation Index in a drought-prone region', Atmospheric research, 212: 130-49.

Ozger, Mehmet, Ashok K Mishra, and Vijay P Singh. 2011. 'Estimating Palmer Drought Severity Index using a wavelet fuzzy logic model based on meteorological variables', International Journal of Climatology, 31: 2021-32.

Palmer, Wayne C. 1965. 'Meteorological drought, Research paper no. 45', US Weather Bureau, Washington, DC, 58.

Potop, Vera, and Martin Možný. 2011. 'The application a new drought index-standardized precipitation evapotranspiration index in the Czech Republic', Mikroklima a mezoklima krajinných structur a antropogennich prostředi, 2: 2-14.

Quinlan, John R. 1992. "Learning with continuous classes." In 5th Australian joint conference on artificial intelligence, 343-48. World Scientific.

Rahmati, O., Panahi, M., Kalantari, Z., Soltani, E., Falah, F., Dayal, K.S., Mohammadi, F., Deo, R.C., Tiefenbacher, J. and Bui, D.T., 2020. Capability and robustness of novel hybridized models used for drought hazard modeling in southeast Queensland, Australia. Science of the Total Environment, 718, p.134656. Sasan Ale-Ebrahim. 2011. 'Land use and land cover classification over a large area in Iran based on single date analysis of satellite imagery', ISPRS Journal of Photogrammetry and Remote Sensing, 66: 608-19.

639

640

641

Salcedo-Sanz, S, RC Deo, L Carro-Calvo, and B Saavedra-Moreno. 2016. 'Monthly prediction of air temperature in Australia and New Zealand with machine learning algorithms', Theoretical and applied climatology, 125: 13-25. INDEX (SWSI) TO ASSESS THE SEVERITY OF DROUGHT CONDITION IN SNOWPACK RUNOFF AREAS." In.: PROCEEDING OF THE WESTERN SNOW CONFERENCE.

Singh, KK. 2007. "M5 model tree for regional mean annual flood estimation." In 5th WSEAS international conference on environment, ecosystems and development, Tenerife, Spain, 306-09.

Tan, Chunping, Jianping Yang, and Man Li. 2015. 'Temporal-spatial variation of drought indicated by SPI and SPEI in Ningxia Hui Autonomous Region, China', Atmosphere, 6: 1399-421.

Törnros, T, and L Menzel. 2014. 'Addressing drought conditions under current and future 
Vicente-Serrano, Sergio M, Santiago Beguería, and Juan I López-Moreno. 2010. 'A multiscalar drought index sensitive to global warming: the standardized precipitation evapotranspiration index', Journal of climate, 23: 1696-718.

Willeke, G, JRM Hosking, JR Wallis, and NB Guttman. 1994. 'The national drought atlas', Institute for water resources report, 94.

Witten, Ian H, Eibe Frank, and MA Hall. 2005. 'Data Mining: Practical machine learning tools and techniques. edition', Morgen Kaufmann, San Francisco.

Yilmaz, Banu, Egemen Aras, Sinan Nacar, and Murat Kankal. 2018. 'Estimating suspended sediment load with multivariate adaptive regression spline, teaching-learning based optimization, and artificial bee colony models', Science of the Total Environment, 639: 826-40. 
(a)

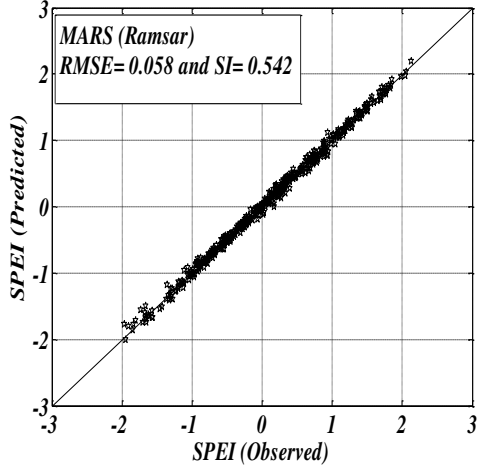

(d)

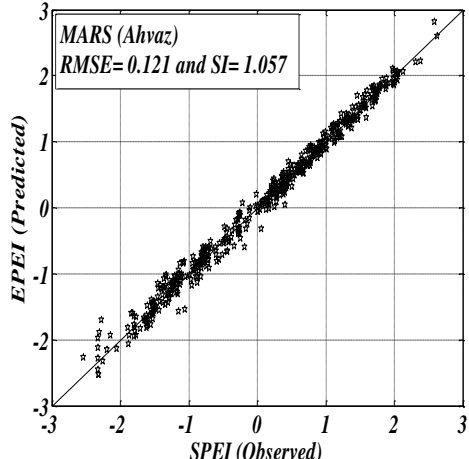

(g)

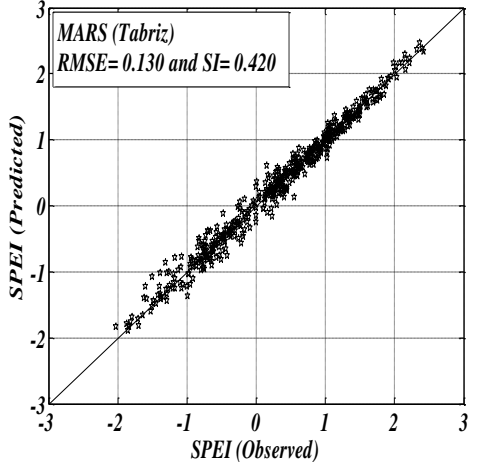

(j)

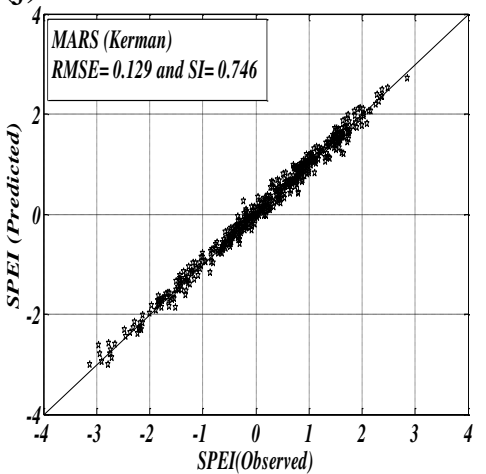

(b)

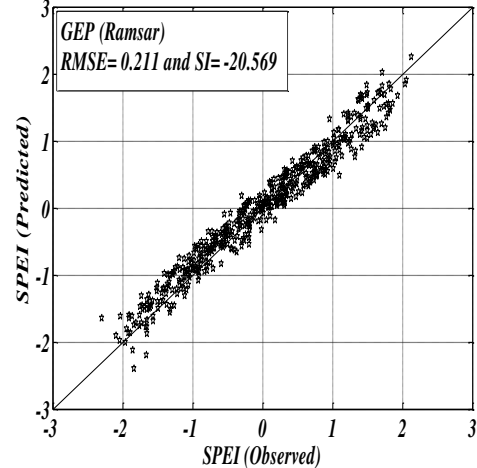

(e)

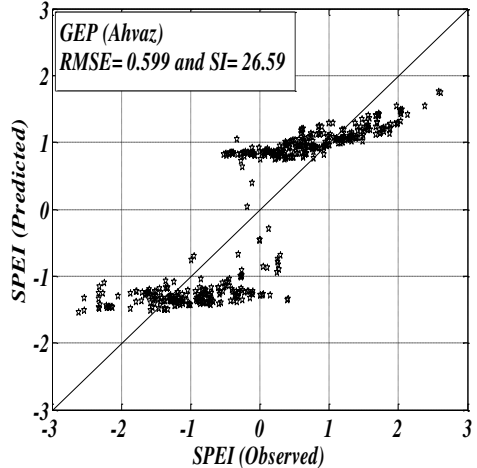

(h)

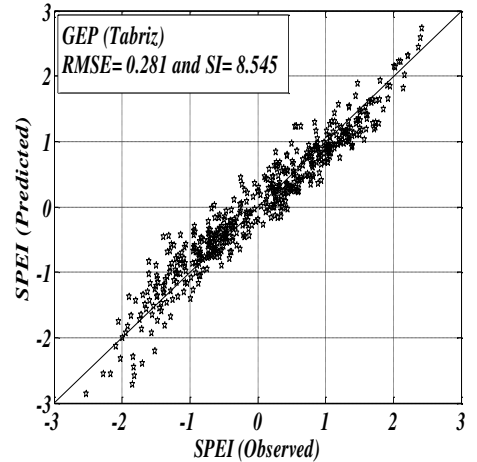

(k)

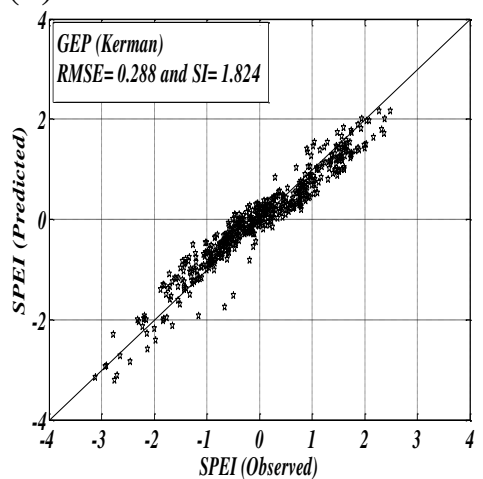

(c)

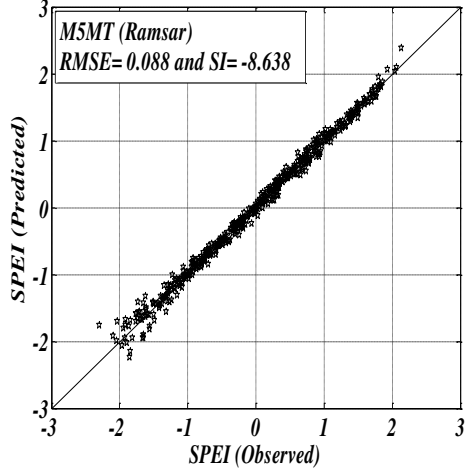

(f)

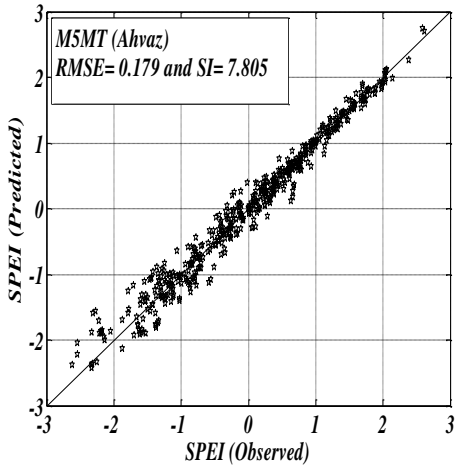

(i)

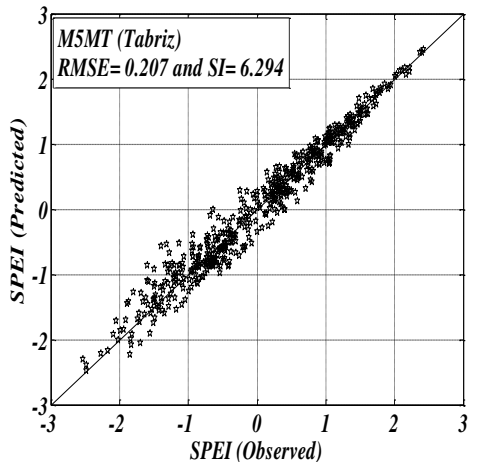

(1)

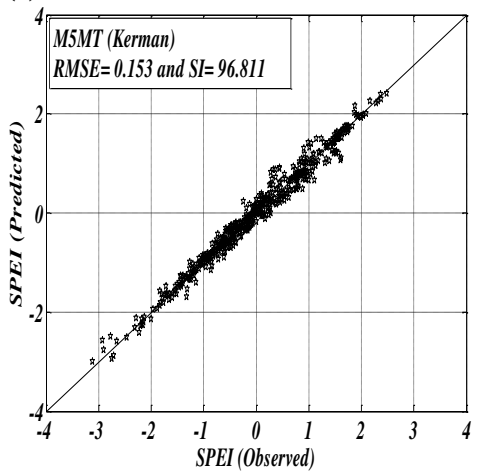

Fig.1. Performance of the proposed models in the training phase 
(a)

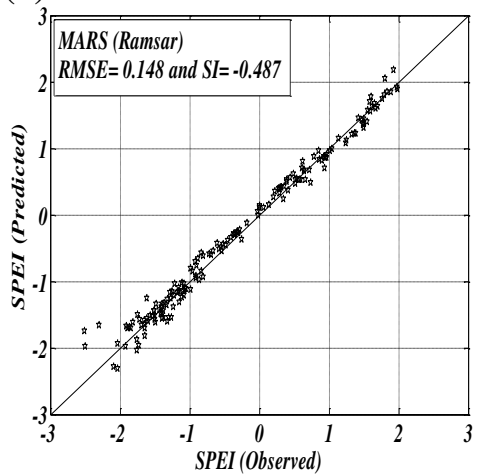

(d)

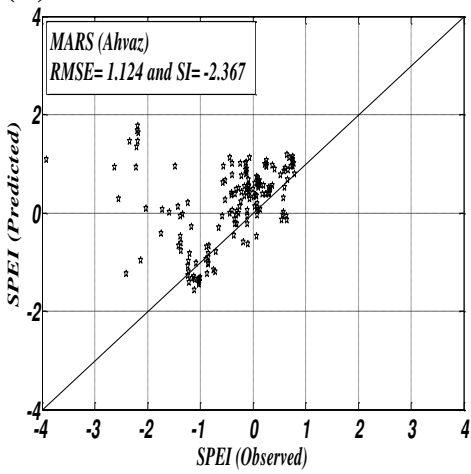

$(\mathrm{g})$

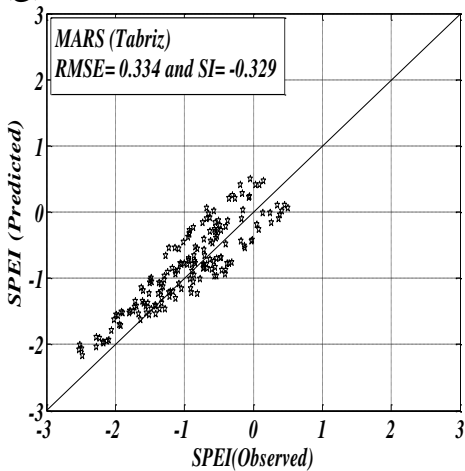

(j)

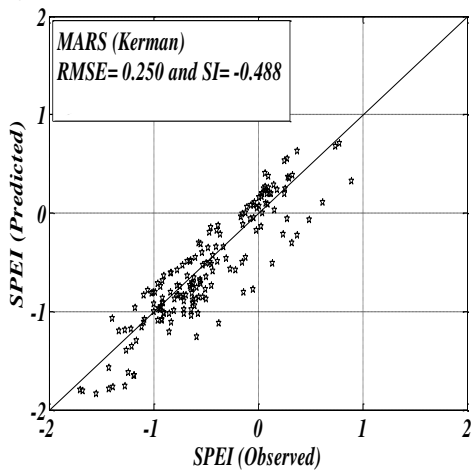

(b)

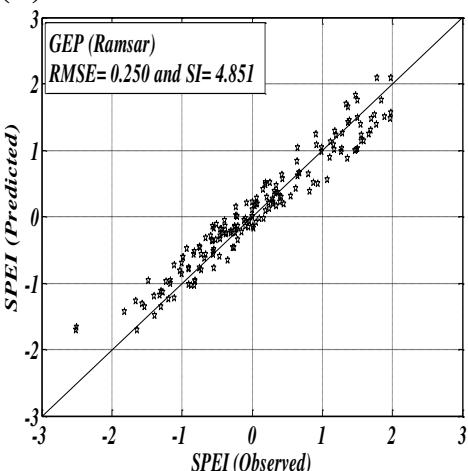

(e)

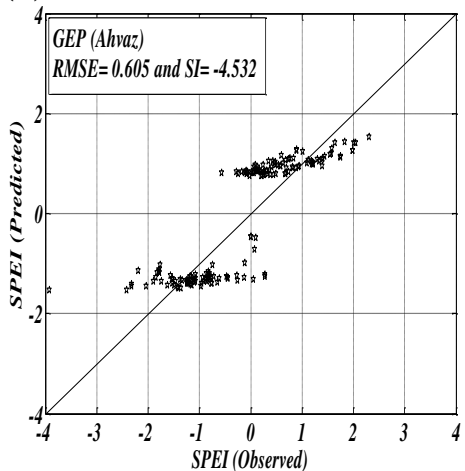

(h)

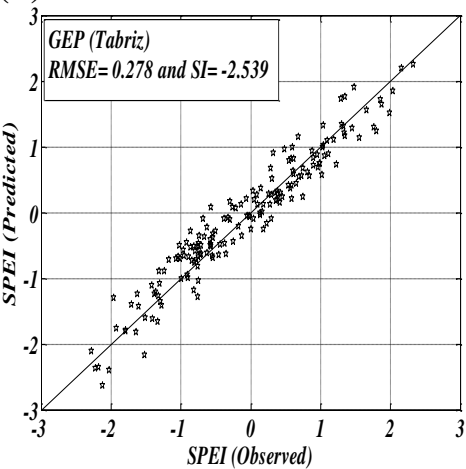

(k)

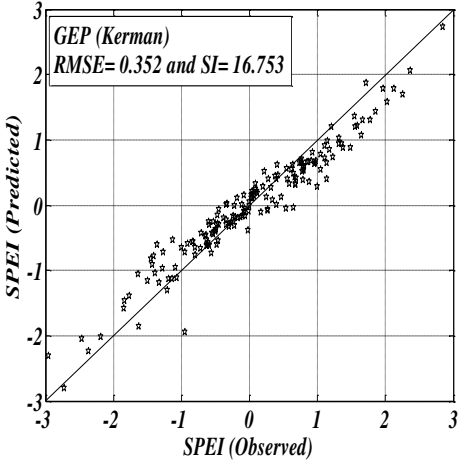

(c)

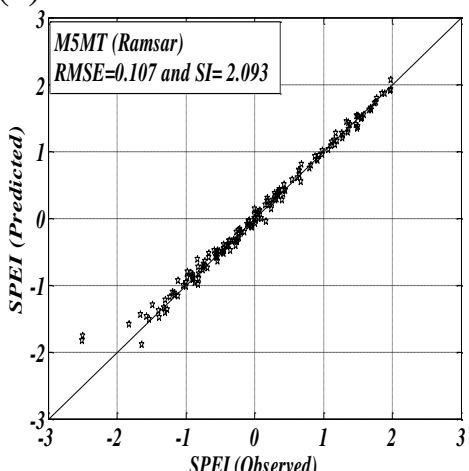

(f)

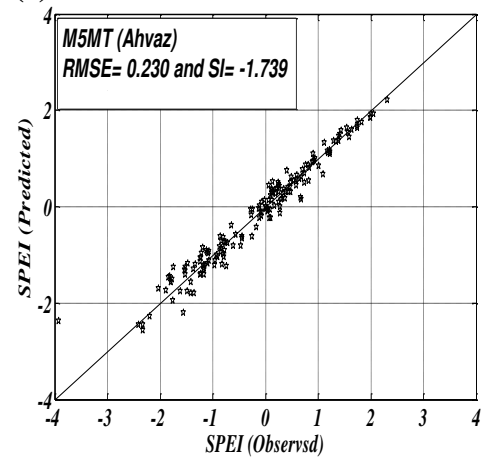

(i)

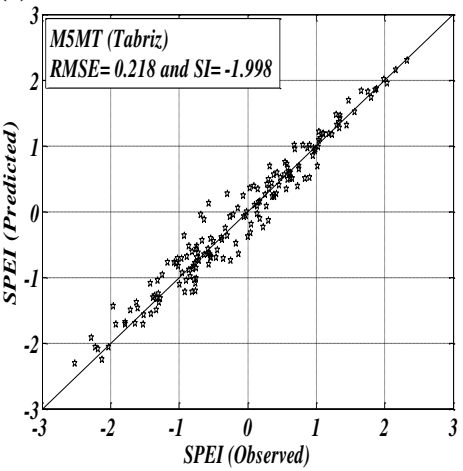

(1)

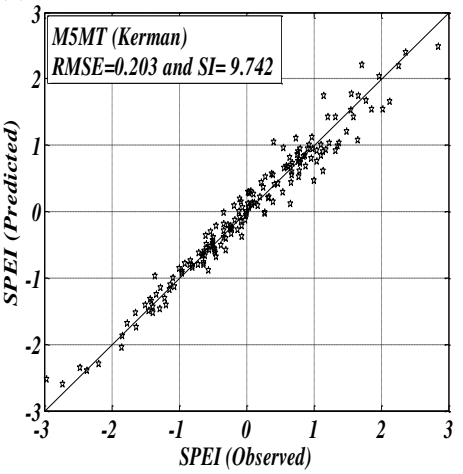

Fig.2. Performance of the proposed models in the testing phase 


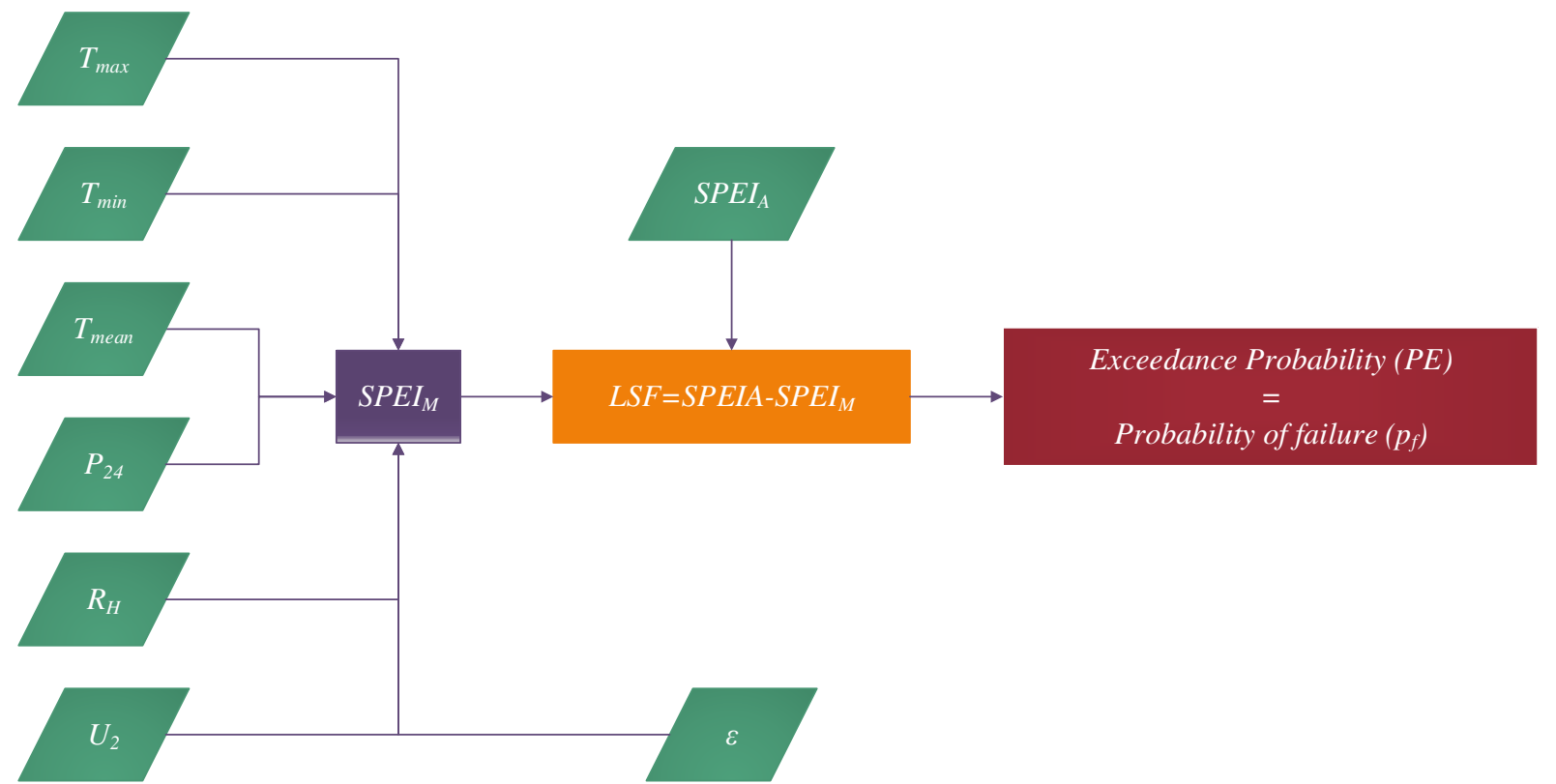

Fig.3. Schema of the probabilistic model for assessing the confidence level for SPEI 
(a)

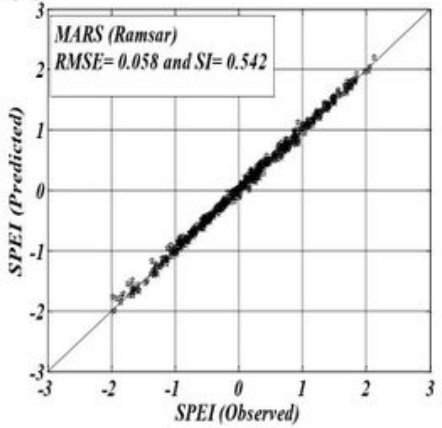

(d)

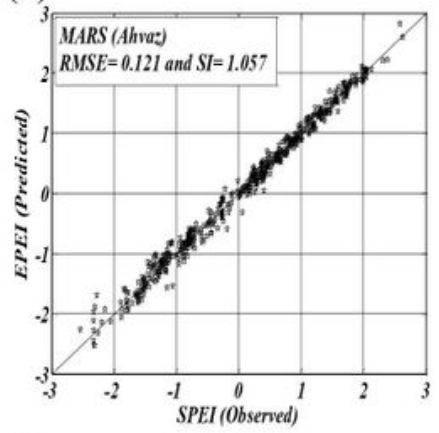

(g)

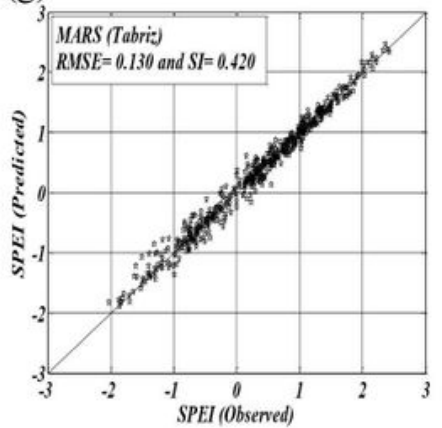

(j)

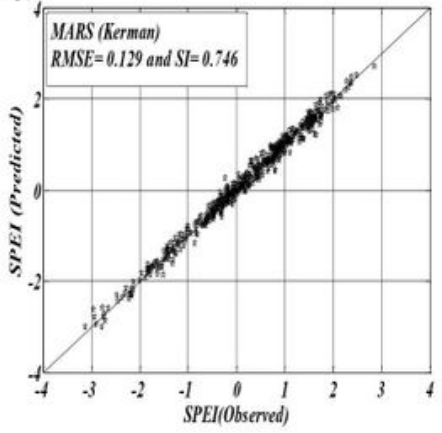

(b)

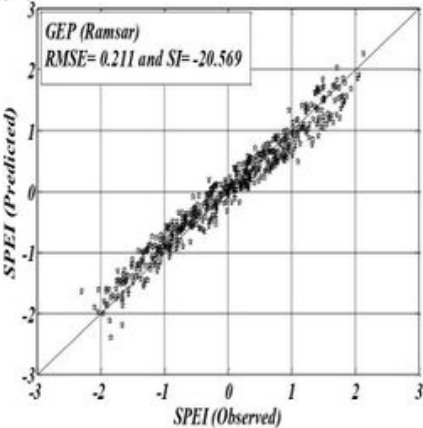

(e)

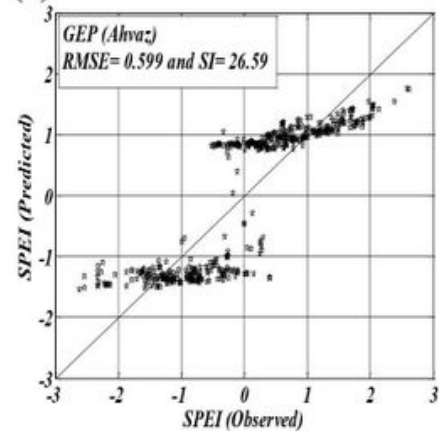

(h)

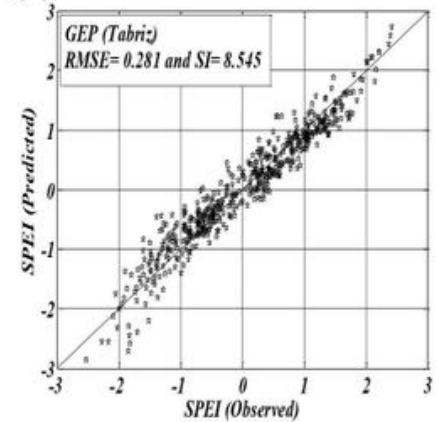

(k)

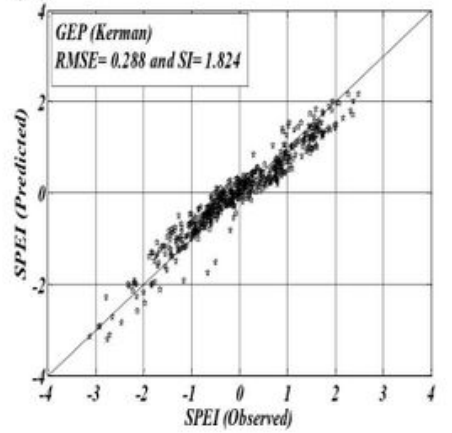

(c)

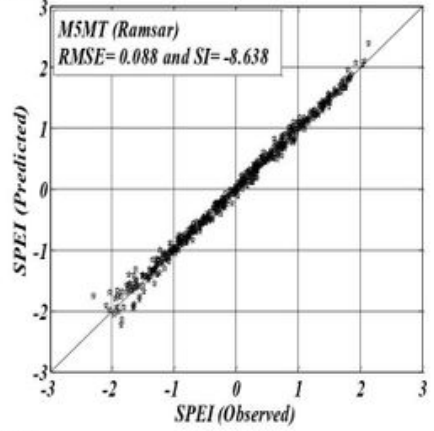

(f)

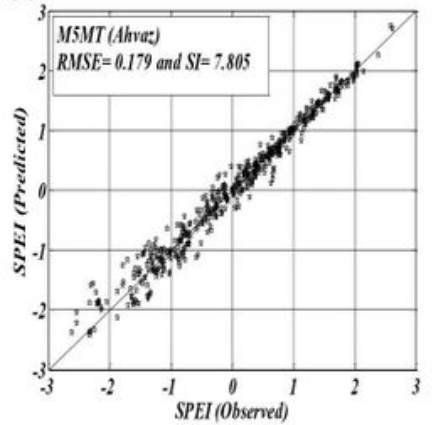

(i)

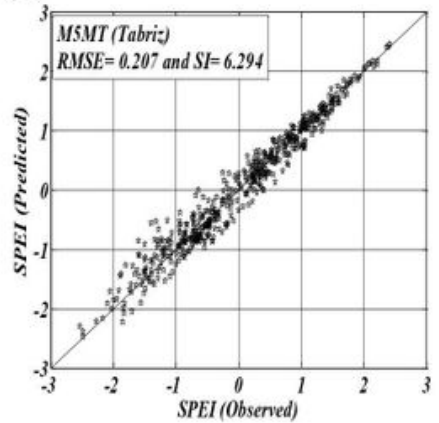

(1)

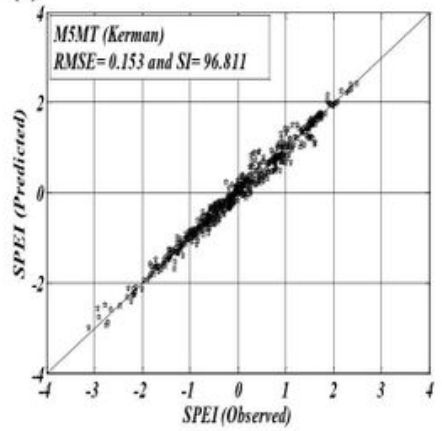

Figure 1

Performance of the proposed models in the training phase 
(a)

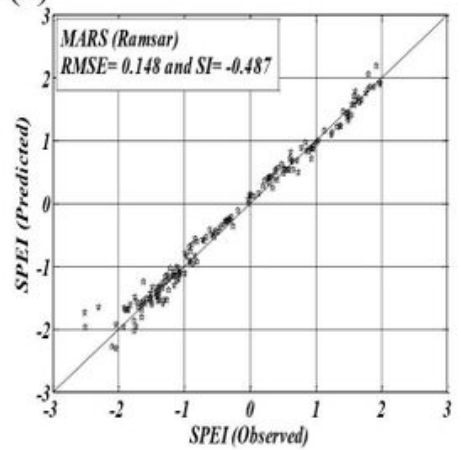

(d)

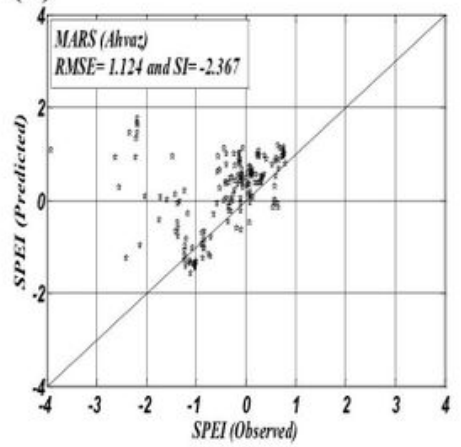

(g)

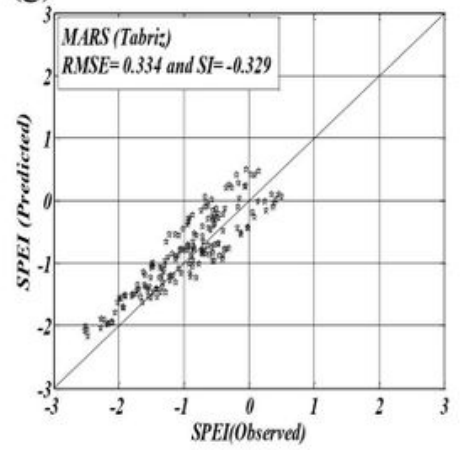

(j)

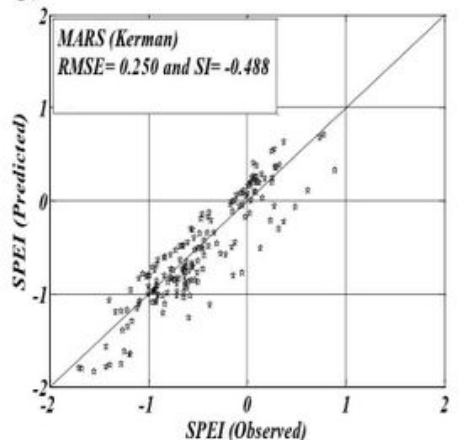

(b)

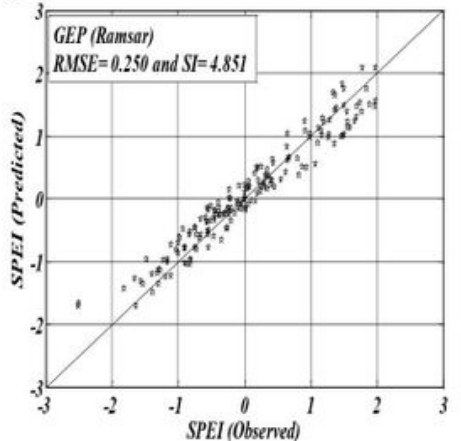

(e)

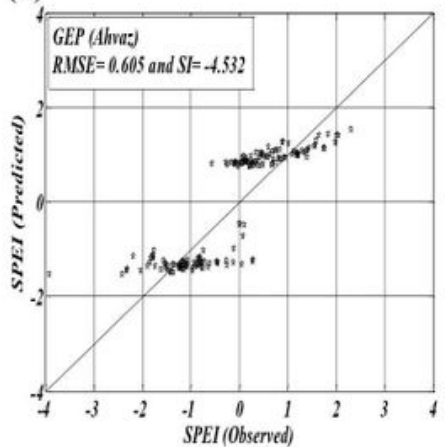

(h)

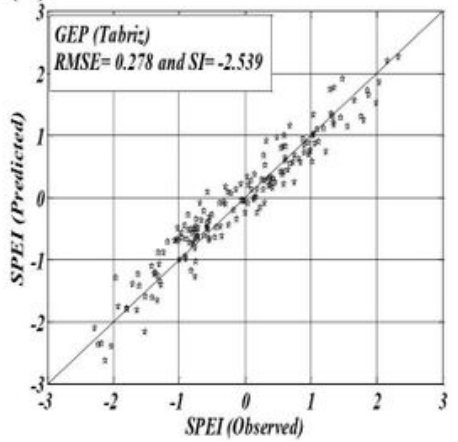

(k)

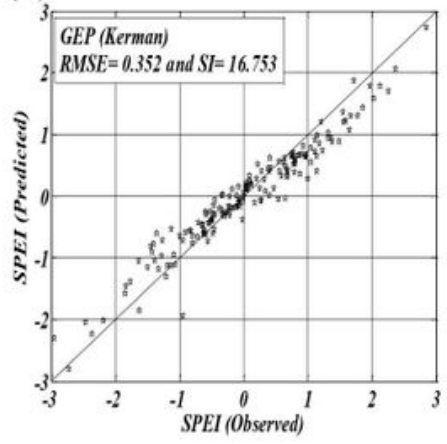

(c)

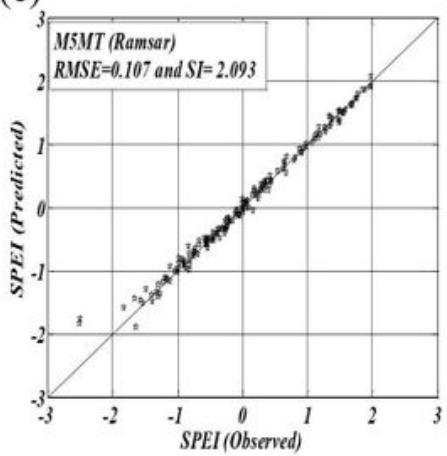

(f)

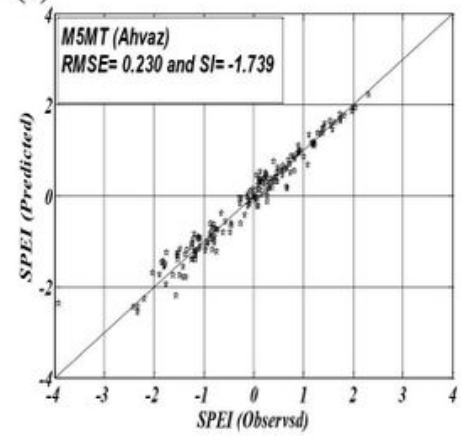

(i)

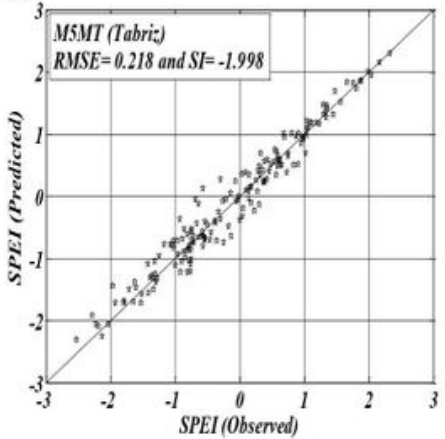

(1)

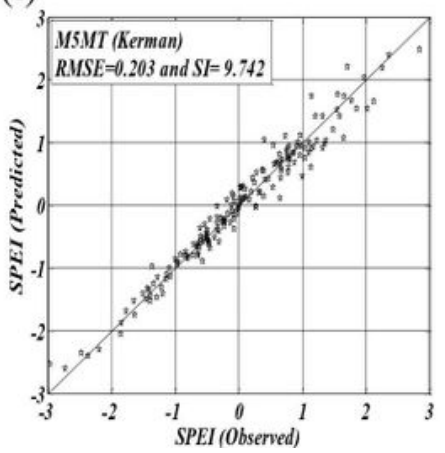

Figure 2

Performance of the proposed models in the testing phase 


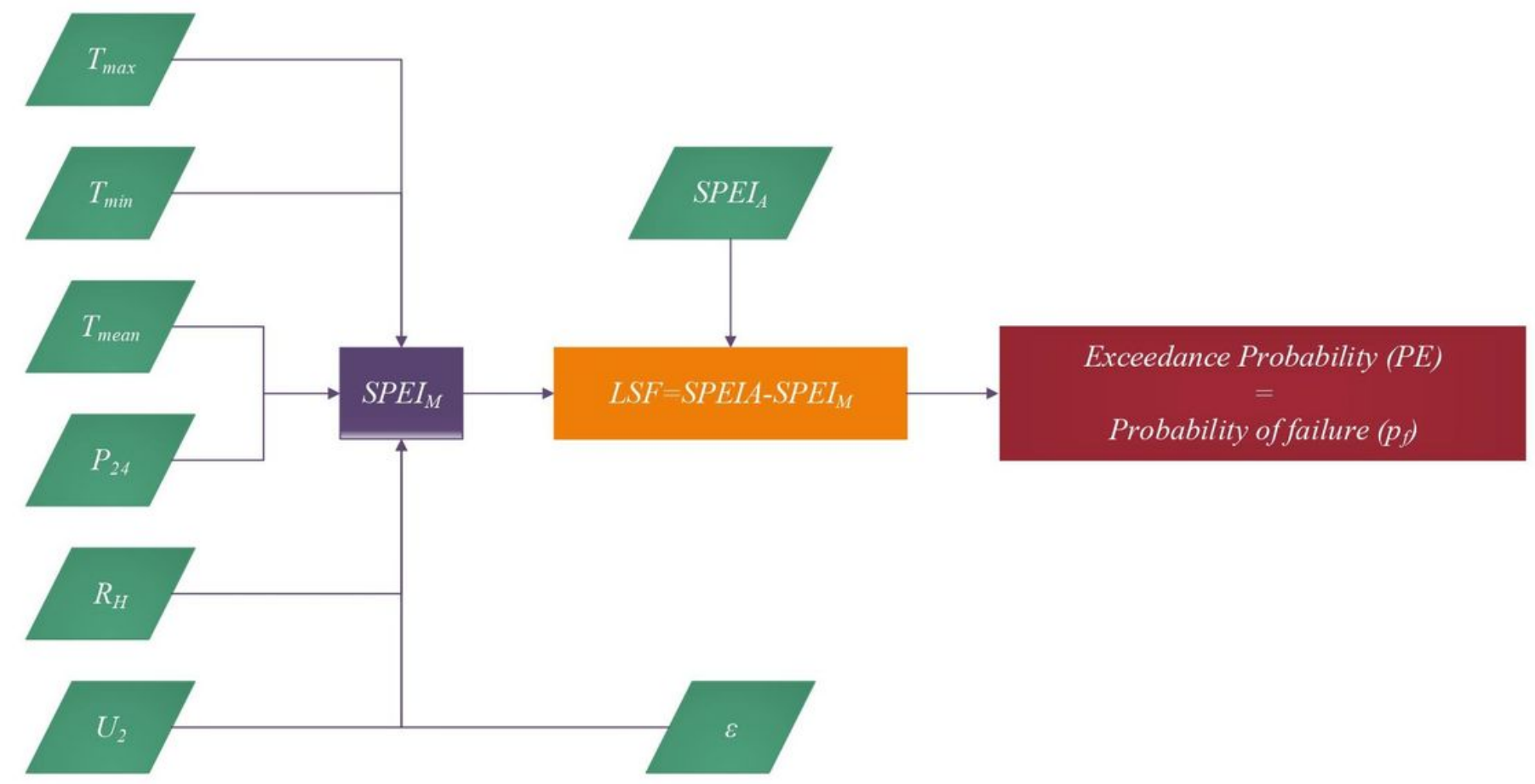

\section{Figure 3}

Schema of the probabilistic model for assessing the confidence level for SPEI

\section{Supplementary Files}

This is a list of supplementary files associated with this preprint. Click to download.

- SupplementaryMaterials.docx

- Table.docx 